\title{
Configuration platform for customisation of design, manufacturing and assembly processes of building façade systems: A building information modelling perspective
}

\author{
Piroozfar, Poorang; Farr, Eric R.P.; Hvam, Lars; Robinson, Dexter; Shafiee, Sara
}

Published in:

Automation in Construction

Link to article, DOI:

10.1016/j.autcon.2019.102914

Publication date:

2019

Document Version

Peer reviewed version

Link back to DTU Orbit

Citation (APA):

Piroozfar, P., Farr, E. R. P., Hvam, L., Robinson, D., \& Shafiee, S. (2019). Configuration platform for customisation of design, manufacturing and assembly processes of building façade systems: A building information modelling perspective. Automation in Construction, 106, [102914].

https://doi.org/10.1016/j.autcon.2019.102914

\section{General rights}

Copyright and moral rights for the publications made accessible in the public portal are retained by the authors and/or other copyright owners and it is a condition of accessing publications that users recognise and abide by the legal requirements associated with these rights.

- Users may download and print one copy of any publication from the public portal for the purpose of private study or research.

- You may not further distribute the material or use it for any profit-making activity or commercial gain

- You may freely distribute the URL identifying the publication in the public portal 


\title{
Configuration Platform for Customisation of Design, Manufacturing and Assembly Processes of Building Façade Systems: A Building Information Modelling Perspective
}

\author{
Poorang PIROOZFAR ${ }^{a, b *}$, Eric R.P. FARR ${ }^{b}$, Lars HVAM ${ }^{c}$, Dexter ROBINSON ${ }^{d}$, Sara SHAFIEE e,f \\ a School of Environment and Technology, University of Brighton, Brighton, BN2 4GJ, UK \\ ${ }^{b}$ NONAMES Design Research and Studies, 1249 F Street, San Diego, CA 92101, USA \\ c Department of Management Engineering, Technical University of Denmark, 2800 Kgs. Lyngby, Denmark \\ ${ }^{d}$ WSP, UK Headquarters, WSP House, 70 Chancery Lane, London, WC2A 1AF, UK \\ e Department of Mechanical Engineering, Technical University of Denmark, 2800 Kgs. Lyngby, Denmark \\ ${ }^{f}$ Haldor Topsøe A/S, Haldor Topsøes Allé 1, 2800 Kongens Lyngby, Denmark
}

\section{Abstract}

Literature on BIM reports case studies and challenges observed when applying BIM in the construction industry. Literature on mass customisation elaborates on methods and experiences of applying modularisation and product configuration including examples from the Architecture, Engineering and Construction (AEC) industry. However, only limited literature is available on how modularisation and configuration can be applied in a BIM context. This paper aims to investigate how the principles of configuration contribute to overcome some of the reported challenges while applying BIM in the AEC industry. This study sets out to explore the principles of platform design, the relations between industrialisation and mass customisation through serialisation facilitated by BIM for a given case of design, manufacturing and assembly processes of building envelopes in the AEC industry. A customisable façade system has been developed to accommodate: 1) The panel components which can lodge different materials; 2) The mullions which can oblige different geometries, 3) The support structure which can accommodate a variation of different geometries and lodge components with different shapes, sizes and dimensions. The identified possible improvements of using BIM, supported by modularisation and configuration, have been tested and evaluated through the case study.

\section{Keywords}

AEC industry; BIM Application; Configuration; Configurators; Mass Customisation; Modularisation; Modularity; Personalisation; Platform Design; Product Families.

\footnotetext{
* Corresponding author: Email: aep15@brighton.ac.uk, Phone: +44(0)1273 642421, +44(0)791 5058426
} 


\section{Introduction}

Major advancements in Building Information Modelling (BIM) have started materialising over the past two decades and their impact on the architecture, engineering and construction (AEC) industry is indispensable. It is not new knowledge that some disciplines in the AEC industry, and within them some specific areas have benefitted from BIM more than the others are. However, full opportunities are yet to be materialised and many more capabilities are yet to be discovered and exploited to the full capacities BIM can offer in the AEC industry.

Although it does not take much to rule out that a house is not a car yet - and that it might never become one - the AEC industry has long been suffering from recurring bouts of Henry Ford Syndrome: Why can't we mass-produce houses, standard, well-designed, at low cost - in the same way Ford mass-produced cars [1]? The fact of the matter is that the myth of Henry Ford - even if it were true at its climax; what some researchers have strongly argued against [2] - is long overdue even in car industry. The AEC industry, therefore, no longer has the luxury to aspire to such a longedfor but probably outdated dream. Emerging strategies in manufacturing have helped AEC transcend into the transpiring post mass-production paradigm but the technological requisites have not yet been up to speed. BIM as a 'philosophy' encompasses novel technological 'tool', nurtures a common collaborative 'environment' and most importantly offers a shared 'platform' [3] - rather a virtual or an 'e-platform - for operationalising such collaboration. It has, therefore, the capacity to speed up this process [4], and successfully leading the AEC industry on to the Industry 4.0 era.

BIM is an Information Technology-enabled (IT) approach that can reduce modelling errors and allows for design integrity, virtual prototyping, simulations, distributed access, retrieval and maintenance of the building data [5]. For design disciplines, BIM is more an extension to Computer Aided Design (CAD); whereas for non-design disciplines, it is perceived more as an intelligent Data Management System (DMS) to quickly and directly take off data from CAD. While there are evident overlaps, BIM application vendors seem to aim to integrate the two requirements [6]. Most recently, CAD packages such as ArchiCAD and AutoCAD have adopted the object-oriented approach [7] with certain capabilities borrowed from the contexts in which object-oriented design has a more established history. Major BIM applications such as Bentley MicroStation and AutoDesk Revit have also started including tools and capabilities which can be developed further to facilitate fully parametrised object-oriented design and production. However, such attempts, although have provided a broad range of potentials - as will be discussed later under the literature review section, have not yet totally come to fruition and this is what this paper seeks to address as a gap in the knowledge.

There are research available on BIM and how the modularised components can facilitate the design of buildings while mentioning the gained benefits $[3,8,9]$. There are few researchers who focus on BIM as a platform that can facilitate modularisation and personalisation process in a totally multidisciplinary environment while involving customer or other stakeholders [4]. This paper develops the findings of a previous independent research project to further investigate how BIM can facilitate wider application of a customer-centric approach based on (mass) customisation and personalisation $[(\mathrm{M}) \mathrm{CP}]$ in the AEC industry. Moreover, the literature review on BIM has not been intended to be exhaustive and only focuses on: 1) challenges and benefits of BIM, and, 2) BIM as a Platform. In this paper, we aim to fill the gap in the existing knowledge using platform design to enable modularisation of façades components as an approach to personalisation focusing on customisable building façade systems. This paper unlocks the potential benefits of BIM tools by proposing a platform to enable BIM to perform as a visualised configuration system in the AEC industry, as other specialised configuration systems are applied in other industries. The configuration system supports product specification processes by providing the user with product customisation choices while 
ensuring that only valid combinations can be chosen [10]. Hence, the main research question of this paper will be: How BIM technology can be adopted to facilitate an (M)CP configurable platform for a customisable AEC product (building envelopes, in the selected case of this study)?

The study starts with a review of (M)CP with particular reference to platform design and products architecture followed by a targeted investigation of BIM most specifically as a platform which can facilitate modularisation for (M)CP. At the next stage, the contextual requirements of a customisable façade will be adopted - from the first stage of this study, further adapted, analysed and developed to define what is required to facilitate an (M)CP platform for a customisable façade. For this purpose, a case-based approach has been developed and deployed to overlay those requirements with capabilities and variations that BIM can offer as a platform. Utilising the systemic approach to a façade - as the system - and its components and elements - as sub-systems, recommendations will be provided as to how such a modular platform can be developed to best suit the context specifics of the product and process in the AEC industry. This will be followed by proposed routes in which future research can be developed so that other benefits of BIM in offering a fully customisable envelope system can be fully utilised in an automated production process in the AEC industry. At service level, developing a web-based or standalone application with an interactive Graphical User Interface (GUI) to enhance the utilisation of BIM which will help promote MC-inspired mind-set in the AEC industry would be the next step forward in this ongoing research project. As its contribution to the body of knowledge in this field, this research will set the scene for a more profound uptake of (M)CP strategies in the AEC industry, where a shift in the production process paradigm is promoted to help the AEC industry to pitch into the Industry 4.0 era more rapidly and more informally.

Practically, this research explains the design and development process of a BIM family which has been developed to accommodate a modularised customisable façade. In the first phase, we elucidated on how the host for this family was developed. This family will be used in this paper as a 'host' for a curtain wall where other elements and parameters are assigned and set to be customisable either independently at sub-system level, in junction with other same level parameters or as a variable dependent on their 'host' - the system. The host accommodates and coordinates the parameters of a series of façade elements and/or parameters within itself [4]. This paper focuses on the platform design to enable modularisation of façades components as an approach to customisable façade system, where the host family will now be utilised to develop:

- The panel components which can accommodate different materials

- The mullions which can take different geometries

- The support structure which can accommodate different dimensions and facilitate different geometries

\section{Research Design and Methodology}

An in-depth critical review of literature has been carried out to establish the correlations between $\mathrm{BIM}$ - as an Information and Communications Technology (ICT) virtual platform - and (M)CP - as a manufacturing strategy which sets out to deploy the full potentials of this virtual platform through principles of product platform and configuration. The aim will be to further develop a methodology for effective application of (M)CP strategies in the AEC industry using BIM capabilities. The systemic approach developed in this study will then be used to further develop the study into its next stage where a structural support system will be developed to accommodate the geometry and location of a curtain wall relative to the building main structural system. This study will also elaborate on the interface system, which needs to be put in place so that the façade support structure can link up with façade elements at one end and to the building structural system at the other end. 
The case study, as a research methodology, comprises all-encompassing methods, covering the logic of design, data collection approaches, and data analysis techniques [11]. In operation management, case study has consistently been one of the most powerful research methods, particularly in testing new theories [12]. Case study research is also the most widely used qualitative research method in information systems research, and is well suited to understand the interactions between information technology-related innovations and organisational contexts [13]. Inductive case-based research has been used both for hypothesis testing and developing new theories. Conducting multiple case study requires attention to the data triangulation as well as observer triangulations $[11,14,15]$. Multiple benefits can be gained from triangulations such as complementary insights, which add to the richness and the convergence of observations to enhance the reliability and validity of findings. The case study method, therefore, was deemed suitable and capable of supporting the objective of this research while answering the "how" and "why" questions.

A universal case study was developed previously looking into the geometry and the form of the host for the product family. It provided a customisable framework for accommodating products, components and materials with a promise of offering capacities to develop in further stages of this research [4]. This proposed universal case will be used in this stage of the study, to test different categorical variations of forms, materials, openings and their relative locations with a special emphasis on it as a configuration platform. It will be demonstrated how devised capabilities in the case as a host can be deployed to support a fully parametrised platform to accommodate a customisable product (a building envelope) in the AEC industry. This study will capitalise on the relations between industrialisation and mass customisation through serialisation of the process. The parametric case will be put into test by adding those elements and components exploring: 1) how the potentials of the generic system developed and explained before can be put into practice; 2) what practical issues and technical problems may be faced with and; 3 ) how those issues can be addressed or resolved. The family developed for this research is used as a platform for application of the modularised architecture of a series of elements and components to achieve a final product line with high degree of flexibility and variation for customisation. The host family and its potential to accommodate modular elements will be elucidated on to help understand, frame and potentially resolve or avoid possible associated problems. This phase of the study is a step ahead on the path to, and can further pave the way towards, a parametric and/or automated approach to Artificial Intelligence enabled (Al-enabled) design in the AEC industry.

3 Challenges are reported in the literature where cases of application of BIM in the AEC industry have been studied. On the other hand, literature on mass customisation evidences methods and experiences of applying modularisation and product configuration with some examples from the AEC industry. However, only limited research have been conducted to date with an aim to explore how modularisation and configuration can be applied in a BIM context. This paper mainly focus on how the principles of modularisation and configuration may contribute to overcome some of the AEC industry challenges while applying BIM. Moreover, the case study is the selected method to identify, test, discuss and evaluate the improvements of using BIM, supported by modularisation and configuration. Product Architecture and Platform

\subsection{Product (Family) Architecture}

Product architecture is known as the way the functional elements of a product are arranged into physical components and how those components interact with each other $[16,17]$. Product architecture development happens during the configuration stage, normally after conceptual design and before parametric design [18]. There are potential linkages between the architecture of the 
product and five areas of managerial importance: 1) product change; 2) product variety; 3 ) component standardisation; 4) product performance; and 5) product development management [19]. Jiao and Tseng [20] describe product family architecture from three perspective: functional, behavioural and structural. They assert that although leading companies have realised that these three views should be taken into consideration when a product family architecture is being designed, this is a very challenging task partially because the knowledge pertaining to those perspectives exists in different organisations [20].

\subsection{Platform Design}

Platform is "a set of subsystems and interfaces that form a common structure from which a stream of derivative products can be efficiently developed and produced" [21: p39]. Thuesen and Hvam [22] suggest, rightly, that working with platforms in AEC industry does not necessarily require a high-tech infrastructure, and that "substantial benefits can be achieved by applying existing construction practices and tools". They follow on to conclude that "This is not to say that IT systems might have an influence on productivity, but productivity can [also]... be reached through a combination of well-defined skills and organisational culture" [22]. In construction industry, however, BIM - which is broadly acknowledged as a new platform which can facilitate achievement of better and more predictable quality, lower cost (in long run and over the lifecycle of the building) and more comprehensive information management processes throughout the lifecycle of the buildings - is, bydefault, established on advanced IT foundations [23]. This however, corroborate Thuesen and Hvam's point regarding the need for "well-defined skills and organisational culture" which are two of major pre-requirements and principles BIM's has been founded on [22].

\subsection{Module, Modularity and Modularisation}

The concept of modularity is believed to have first emerged in the computer industry in 1960's [24] and then widely spread to manufacturing. However, originally published in French in 1950s, Le Corbusier's Le Modulor [25] and Le Modulor II [26], were the first attempts on dimensional coordination which gave rise to modularisation as a basis for other industrialised and non-traditional methods in post WWII Modern Architecture [27]. The concept of modularity in other industries, however, is primarily different from what was initially conceived in the AEC industry. Modularity is rather concerned with components than mere sizes and dimensions and involves the platforms and interfaces design to help facilitate customisation of end-products and services [28]. In principle, a module is understood to be a physical, conceptual or virtual clustering of some elements and components. Hence, modularity can be perceived as the concept of breaking down a system into independent parts to accommodate modules and the modules that can be treated as logical units [29-31]. Modularity has been defined as the relationship between a product's functional and physical structures such that: 1) there is a one-to-one or many-to-one correspondence between the functional and physical structures; and 2) unintended interactions between modules are minimised $[19,32,33]$. As a rather conventional definition of modularity, this definition can be updated by adding what more recent technological advancements (e.g. ICT and automation, etc.) have to offer throughout the design, manufacturing and assembly processes. Interestingly, [34] suggest that while direct impact of mass customisation on supplier quality integration is not significant, product modularity directly improves supplier quality integration [35].

\section{4 (Mass) Customisation and Personalisation}

There has been a paradigm shift from mass production to mass customisation and thereafter into individual customisation or simply customisation [36], hence the choice of the novel combination (Mass) Customisation and personalisation or (M)CP in this paper. Customisation is known to be an element of personalisation and sets out to elucidate on how the different constituents of 
personalisation - customer interactions, analyses of customer data, customisation based on customer profiles and targeting of marketing activities - are linked [37,38]. For (M)C to materialise effectively, there is an array of requisites ranging from pure cultural, behavioural and management changes required to nurture the shift [39-44], to pure technological changes [40,41,43-49] whether in form of ICT support infrastructure or those directly applied to the manufacturing process.

\subsection{Challenges of customisation}

The increase in product variety - what it is particularly evident in the examples of Engineer-To-Order (ETO) companies - leads to an increase in complexity range. ETO companies create highly engineered complex product variants that are engineered to the specific requirements of a customer [50]. ETO variants are generally reflecting a particular highly individual customer requirements. Managing variety throughout the entire products supply chain is one of the major challenges in customising the products. Grouping similar variants into families is a fundamental enabler of designing, planning and producing variants efficiently [37]. Product families contain variants of the products and their parts, components and configurations [51,52] in order to better meet the diverse needs of today's highly competitive global marketplace, to increase variety, shorten lead-times, and reduce costs $[53,54]$. One of the highly recommended solutions is configurators as specialised systems that support product customisation by describing how predefined entities (physical or nonphysical) and their properties (fixed or variable) can be combined $[55,56]$. Product configurators as an IT smart solution can help solve the challenges in product customisation in ETO strategies such as AEC industries.

\subsection{Product configuration: a smart IT solution}

Product configurators can be applied to support the decision-making processes in the sales and engineering phases of a product, where the most important decisions regarding product features and product costs are made [55]. Configurators enables companies to develop product alternatives to facilitate the sales and production processes [57] by incorporating information about product features, product structure, production processes, costs and prices [58]. This information is modelled in configurators during their implementation [58]. Automation of engineering processes is increasingly prevalent in multiple lifecycle phases such as design, manufacturing and service support [59]. The configurators receive the individual customer requirements, configure the product based on the defined solution space, perform the calculations and finally generate all the necessary outputs including proposals, bills of material/quantity, price calculation sheets and even $\mathrm{CAD} /$ technical drawings. Widely used in various industries, configurators can bring substantial benefits, such as shorter lead times for generating quotations, fewer errors, increased ability to meet customers' requirements regarding product functionality, the use of fewer resources, optimised product designs, less routine work and improved on-time delivery $[10,40,45,58,60]$.

\subsection{Modularity in (M)CP}

Product family architecture is an established strategy in customisation [61,62]. Although harder to argue for its benefits for individual customisation and configuration, modularity is at the core for at least one of five fundamental strategies to achieve mass customisation. Nonetheless, Pine believes modularity is the pillar of mass customisation regardless of specific approach or strategy [63-65] regardless of the chosen strategy. At bare minimum level, modularity provides a means for standardisation of repetitive components. Six types of modularity have been introduced in customisation research literature $[63,66,67]$, of which Bus Modularity and Sectional Modularity are the most advanced, the most flexible, and therefore probably the most difficult ones to achieve (Figure 1). Due to the level of complexity involved, these two strategies however, are most likely to 
be applicable to (M)CP in the AEC industry; whereby modularity can be realised in its manufacturing sense rather than what was traditionally understood of modularisation in architecture [28].
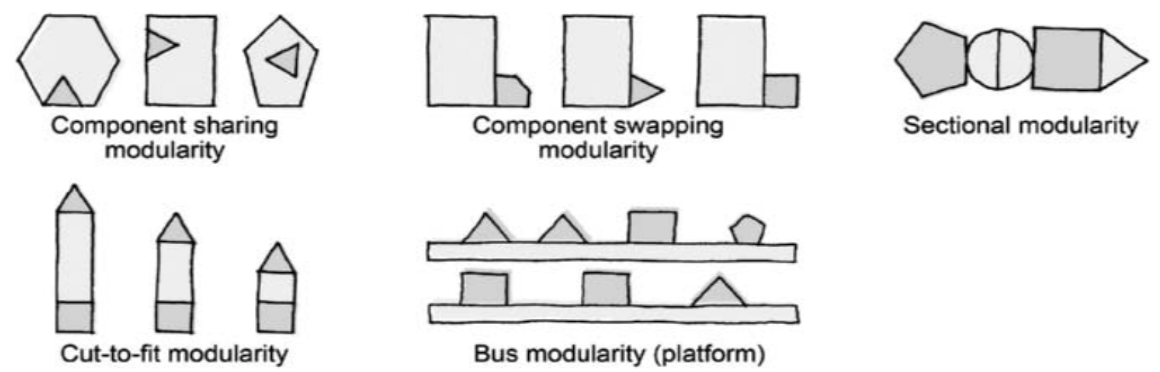

Figure 1: Types of modularity $[32,63]$

\section{Building Information Modelling (BIM)}

A BIM is a digital representation of physical and functional characteristics of a facility. As such, it serves as a shared knowledge resource for information about a facility forming a reliable basis for decisions during its life cycle from inception onward. A basic premise of BIM is collaboration with different stakeholders at different phases of the life-cycle of a facility to insert, extract, update or modify information in the model to support and reflect the roles of stakeholders. The BIM model is a shared digital representation founded on open standards for interoperability [68].

\subsection{BIM Advantages and Disadvantages}

The BIM has had an irreversible impact on the construction industry. It has offered some advantages without which construction industry was not able to respond to the level of project complexity, accuracy and timeliness as it does now. However, it has its own disadvantages as well. Eastman, et al. [3] outline 19 benefits in 4 different stages of construction process, of which the ones with some potential to benefit from customisation (building upon the product platform and configuration) are as follows:

- Increased building performance and quality

- Improved collaboration using integrated project delivery

- Earlier collaboration of multiple design disciplines

- Use of design model as basis for fabricated components

- Better implementation of lean construction techniques

A clear account of BIM advantages is provided by FMI/CMAA 2007 Eighth Annual Survey of Owners [69]. Those advantages which can be extrapolated to what customisation (with respect to product platform and configuration) can support include:

- Broader strategic perspective and innovation

- Easier to achieve process standardisation

- More reliable compliance with specification and regulations

- Improved communication and collaboration amongst project participants

- Greater productivity from labour and assets

- Decreased labour costs

The same report also identifies some hurdles on the way of BIM implementation, of which those with some potential negative impact on customisation consist of:

- Lack of industry standards 
- Greater system complexity

- Different needs across stakeholders (which is the core concept of customisation)

- Poor integration with existing systems

- Unclear business value and ROI [return on investment]

In the UK, although the general belief is that the UK Government Construction Strategy's mandate of 2011 for fully collaborative BIM Level 2 being utilised in all public projects by 2016 has not yet been fully materialised, the Digital Built Britain Strategic Plan for BIM Level 3 was published in February 2015 and the NBS National BIM annual surveys show a continuous growth and a solid progress in BIM culture in the UK construction industry year on year since 2012. We will use the reported benefits and challenges mentioned above further to discuss the value of the current research in highlighting the benefits and overcoming the challenges.

\subsection{BIM as a Platform}

The research on both digital and non-digital forms of platform is not few and far between [70]. BIM has been researched as a generic platform as opposed to a mere tool or a broad environment to support an almost total overhaul of all activities traditionally performed in the AEC industry [3]. BIM-server as a multi-disciplinary collaboration platform has been reviewed where it was suggested that it should not be limited to functional and operational requirements and should provide technical features to support information sharing, communication media, process management, exploration space, privacy and flexible system configuration [6]. BIM has also been studied where different associations of it with or as a platform has been attempted on; 1) in an integrated platform between FM (Facilities Management), BIM, BMS (Building Management System) for front-end sensor data visualisation [71]; or 2) with a planning and operations control software for automated construction developed to facilitate interoperability between the construction system and BIM as a platform [72]; or 3) where an ontological approach has been used to develop a freeware platform for accommodation and rapid development of BIM applications with reasoning support [73]. It has also been promoted as an IoT (Internet of Things) enabled platform for on-site assembly of prefabricated construction [74]. Nonetheless, BIM is a shared platform for creating, maintaining and reuse of information throughout the lifecycle of a building [75] which serves as a collaborative database for management of buildings throughout design, construction and post-occupancy phases [76]. This platform, has been utilised in different capacities sometimes with the main focus being outside the digital domain; for instance, in concrete reinforcement supply chain, where it has been evaluated in four areas of design and modelling; editing, updating and optimisation; interoperability; and project and construction management tools where improvements have been proposed [77]. It has been suggested that if " [BIM (as a platform) is] coordinated, integrated, and preserved properly, [it] can be used to perform different multidimensional analyses to support various business operations, driving intelligent decision-making in the AEC projects" [77, p:1].

BIM, however, has not yet widely been used as an open-architecture platform specifically developed as a building product or component configurator. It is believed that the shift towards object-oriented CAD in the AEC industry has generated more interests in BIM [6] because of the potential capabilities that BIM has to offer. However, despite this positive tendency, it does not seem that product platform design (and the associated configuration processes) have been yet benefitted from operational research in the AEC industry as much as in the product design, industrial design or manufacturing industry. This gap in the knowledge is what this study aims to fill with a case specifically developed through serialisation of the flow of information to demonstrate BIM capabilities as a configurator and to investigate relations between industrialisation and 
customisation; what can serve as a step towards full automated or Al-enabled approaches to and solutions in the AEC industry.

\section{Model Developmental Workflow}

This study uses a case-based analysis approach where a 'universal model' has been developed to fully demonstrate how BIM can facilitate (M)CP in the design, manufacturing and assembly processes of a building envelope system. By 'universal model', we mean that the proposed model can easily be rolled out and applied to any real-case scenario and is not bound by the limitations that one single case study might impose on the study's knowledge claims. The following steps have been followed as a procedural workflow to develop the case study (Figure 2):

- Creating the building structure and Tier 1 surface generator (The Platform)

- Creating the Tier 2 parametrised panels (The Modules)

- Creating the Façade Support System: Mullions and Support Frame (The Interface)

- Assemblage

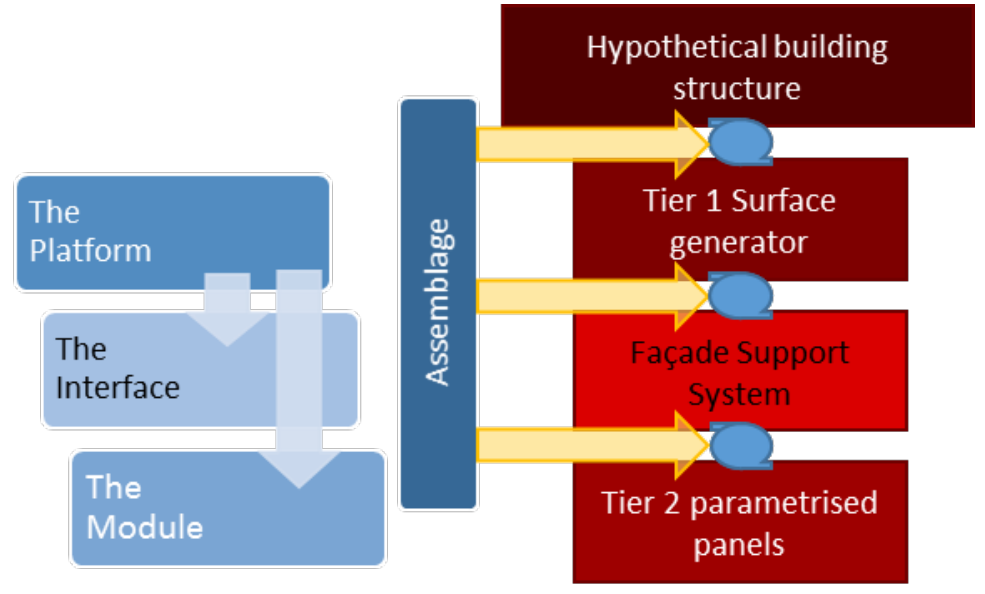

Figure 2: Procedural workflow for development of the case study

The development framework will be explained in details in the next section.

\section{Developing the Model}

An industry standard BIM application was utilised to develop a case-based analytical design typology so that it can accommodate variation requirements of a customisable curtain wall system. The systems theory was used as an underlying theoretical framework to help focus on the levels intended to be addressed in this study where: 1) the building was assumed as the 'super-system' that contains the façade system; 2) the façade was taken as the 'system'; with 3) the façade materials and components at the 'sub-system' level. This study focuses on the sub-system levels, exclusively on how the structural supports and elements at this level (sub-system) connect the façade (system) to the building (super-system) (see Figure 3).

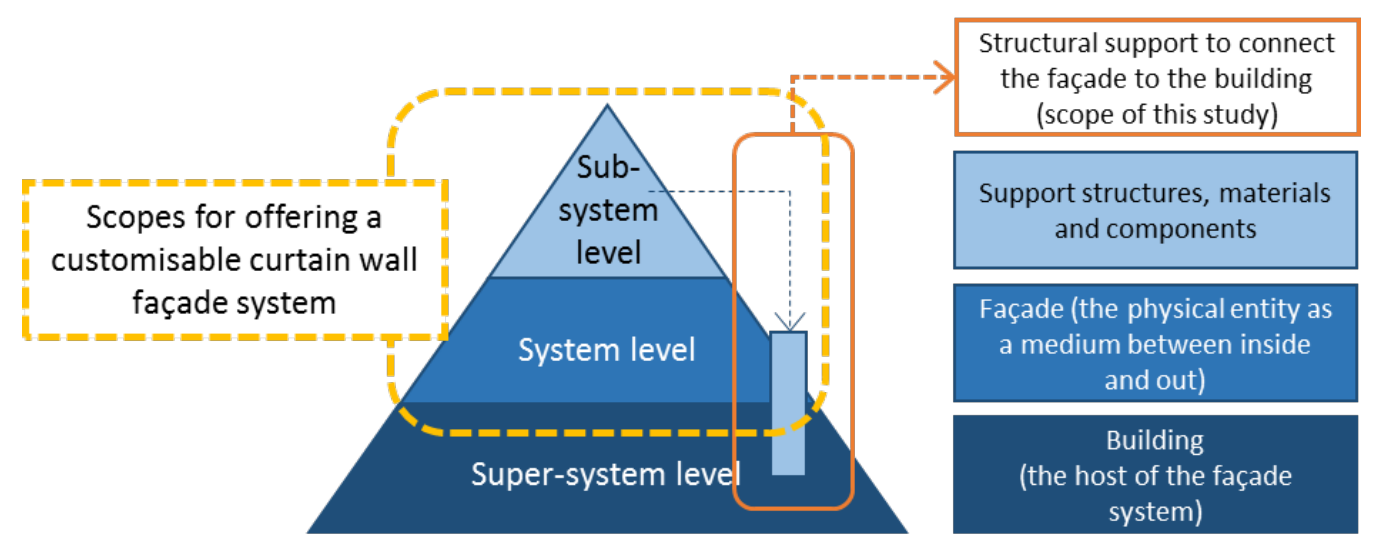


Figure 3: Possible scopes for applying (M)CP on a façade system and the focus of this study

The system level variations of the form for a curtain wall façade are shown in Figure 4. This study will only focus on the non-planar façades as planar façades are relatively straight-forward and can be dealt with using much easier methods and solutions most of which are dated pre-BIM era. Therefore, the generative form of the façade as the host for the building façade for which the structural supports and connections will be addressed in this paper are single- or double-curved surfaces.

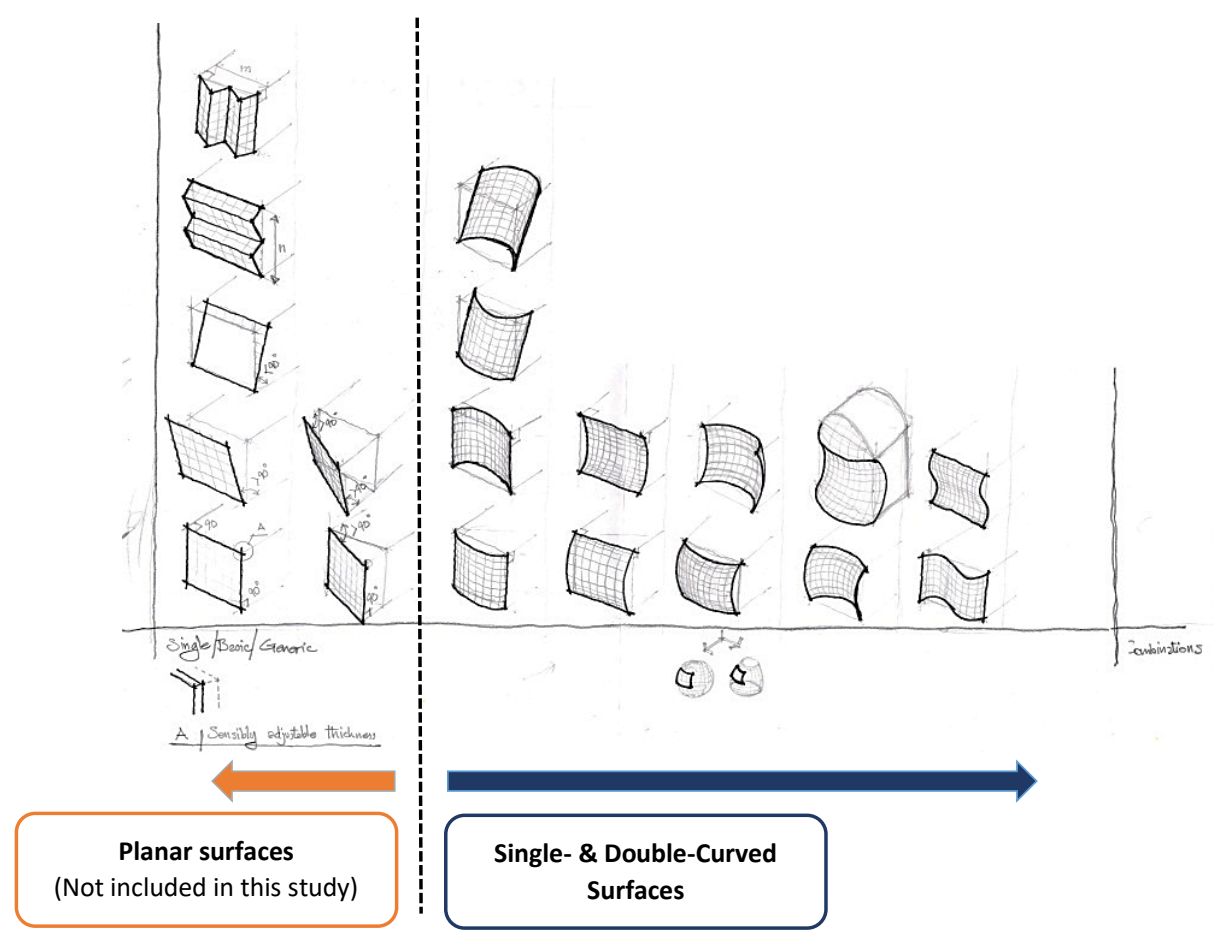

Figure 4: Variation of form at system level; façade form as the 'host' for sub-system level variables

Figure 5 shows the scope and application of this phase of the study in more details.

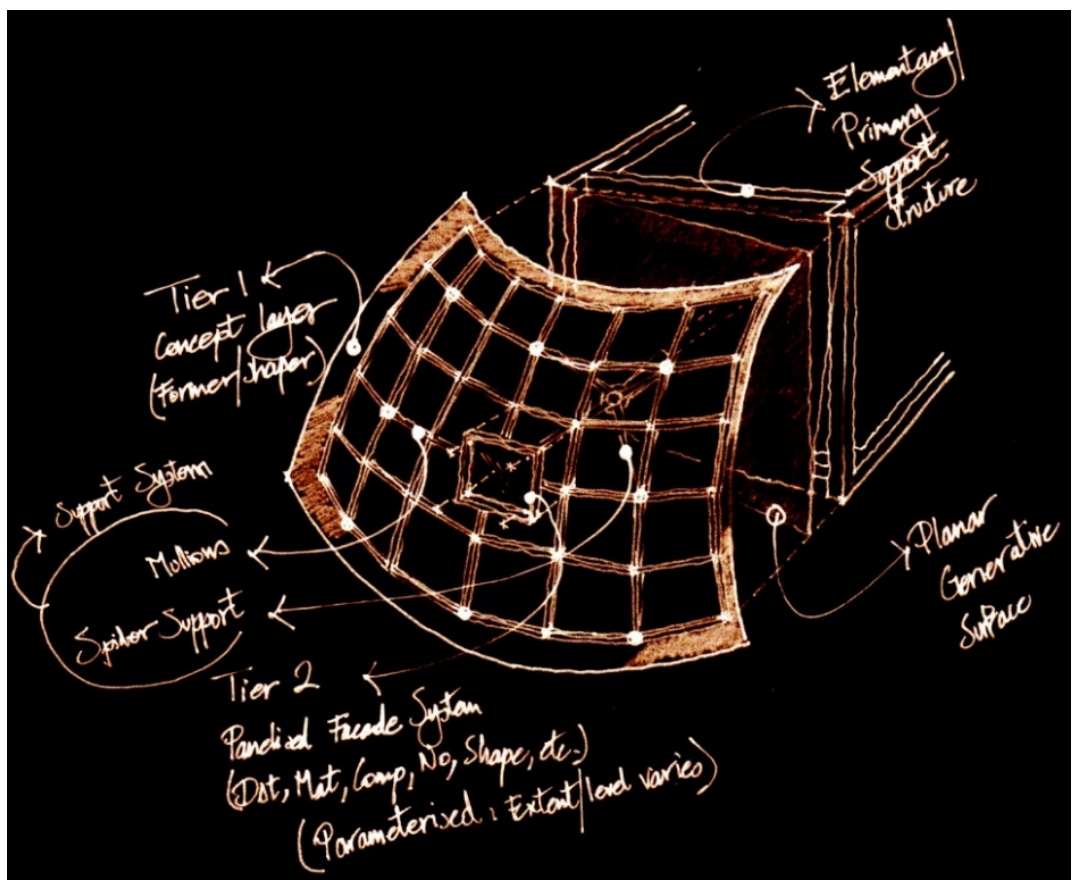


Figure 5: The conceptual development of layers, tiers, components and elements of the proposed façade system

The primary super-structure is the building's structural frame through which the façade system will be supported. Then, there would be a planar generative surface for indicative purposes only that shows the angles, vectors, directions and sizes which are used to form the main double-curved façade. A 'Tier 1' layer then will be shaped - as a form-generator - to host the support structure, the façade components, their elements and materials. 'Tier 2' will then be formed with the panelised system whose parameters include form, shape, size, distance, material, components, and elements as well as the numbers of similar or identical units. The support system (shown as mullions and spider joints in Figure 5) is needed to link up the 'Tier 1 ' layer (which hosts the façade and its associated components, elements and materials) to the building structural system. The support system is the main focus of this study. However, aiming to put the development process of this support system into context properly, a basic building and a basic façade system have also been developed to fully cover the issues which need to be taken into account when a customisable façade system is to be developed.

\subsection{Creating the building structure and Tier 1 surface generator (The Platform)}

A conceptual mass made of flat panels will be constructed of two splines fixed at the upper and lower levels with set centre point as half width (Figure 6a). This will serve as the building structure. A curve will then be created as the Tier 1 surface generator to host the façade. Each part of the curve is made of a spline created through three points to provide proportionate degree of freedom to accommodate the form variations associated with a double-curved surface. Each point is generated by parameters for offset from the flat panel and mid-point offset. The mid-point height needs to be configurable by an independent parameter (Figure 6b).
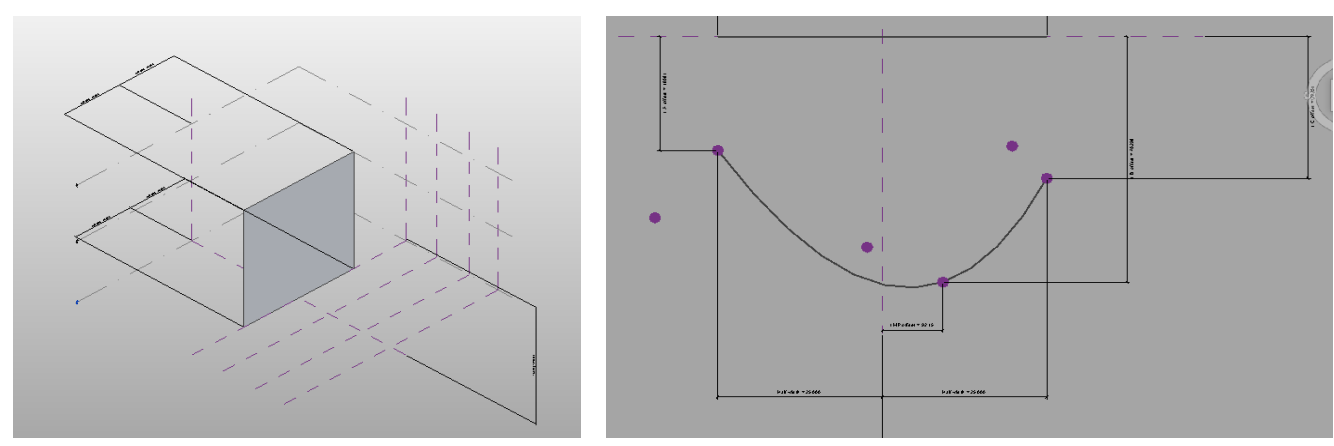

Figure 6: a. Conceptual mass made of two flat panels, and b. Tier 1 surface-generator as a host for doublecurved façade system 

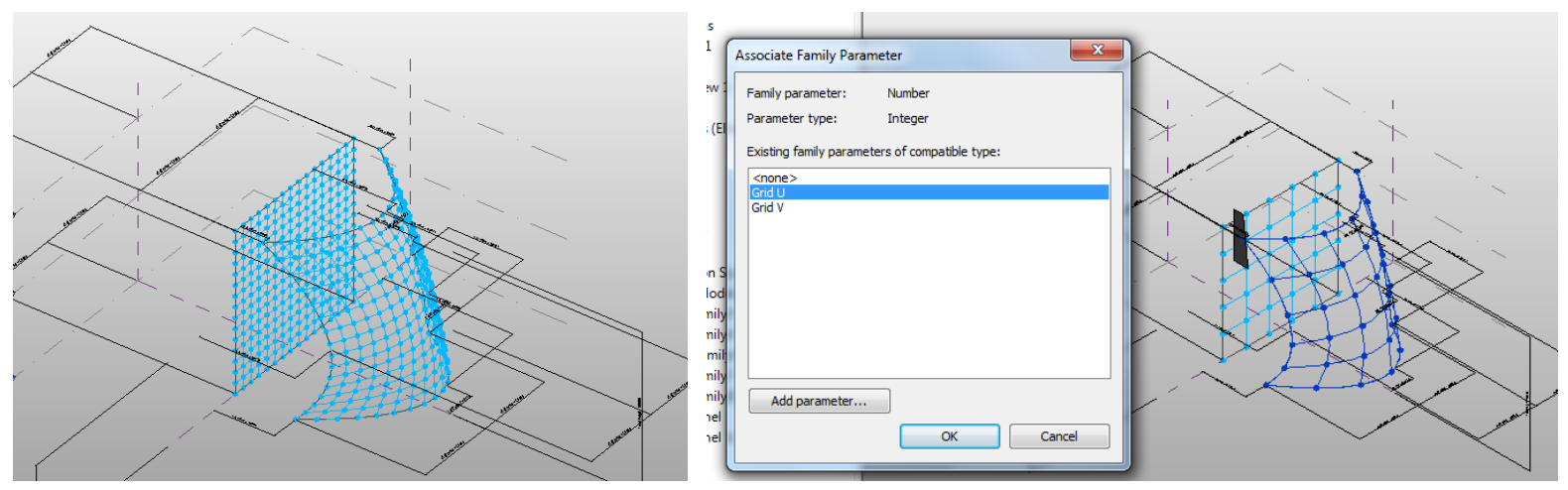

Figure 7: a. Double-curved surface divided into a grid structure, and b. Parameters are assigned to both panels (planer and double-curved) for connecting them together using the support system

At next step, the surface needs to be set up, so that it can accommodate the parametrised components. The double-curved surface created in the previous step, is now divided and a grid number is set as a parameter of grid in two different $X$ and $Y$ axes directions. The nodes on each corner of each surface can be seen in Figure 7a. At the next step, basic parametric properties will be added to the grid spacing by setting the grid values to family type parameters for both panels (Figure $7 b)$.

This will provide the opportunity to assign different parameters to those individual elements and also to link the building structural system to the façade support structure at a later stage.

\subsection{Creating the Tier 2 parametrised panels (The Modules)}

To create the parametrised panel, a new generic model using an adaptive family was created with four non-associated adaptive points (Figure 8a) where the points were joined with a model spline (Figure 8b).
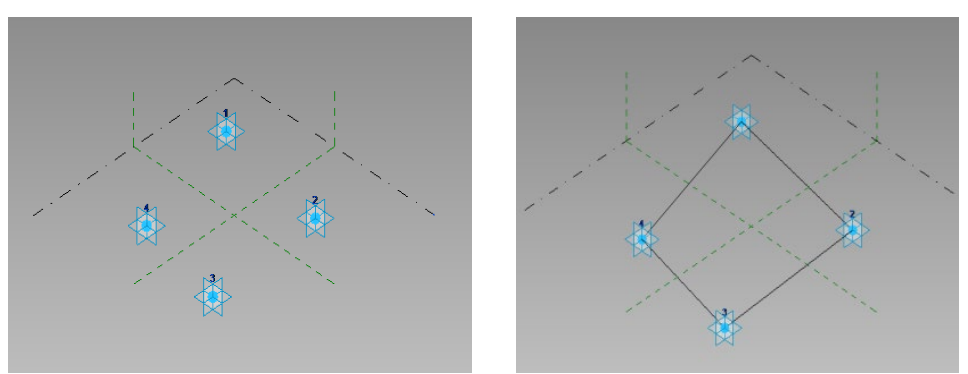

Figure 8: a. Four non-associated adaptive points are created and used for, $b$. Creating the base for the parametrised façade panel using four model splines

Then two masses will be generated on top of each other, using the 4 splines created before (Figure 9a) with the top dimension defined as the 'panel thickness' and the bottom dimension as 'panel offset'. The panel material will be configured as a family parameter of material (Figure 9b).
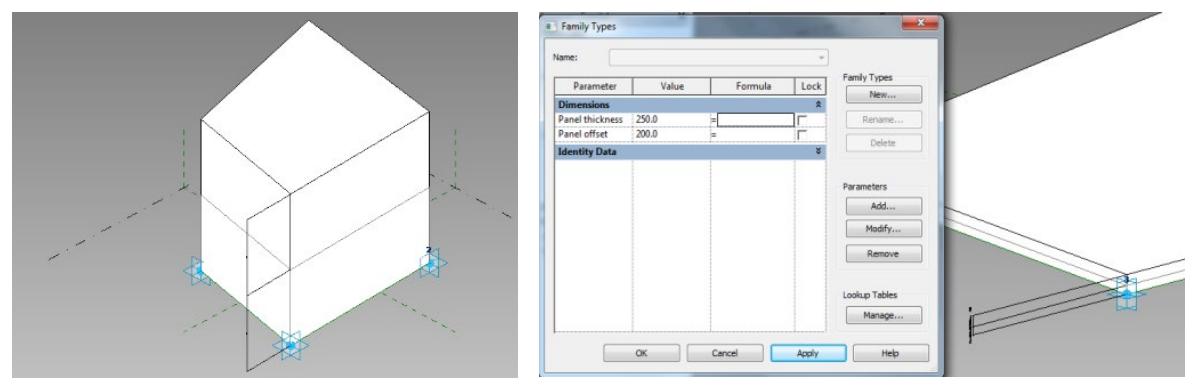

Figure 9: a. Two stacked-up masses created, b. dimensions and parameters are set and defined 


\subsection{Creating the Façade Support System: Mullions and Support Frame (The Interface)}

Mullions were created using a new generic model and set as an adaptive family. A circle was created on the base plane whose centre offset and radius were parametrised to accommodate different sizes and lengths. To create a support frame, individual support arms were developed using a new adaptive component generated with two non-associated adaptive points (Figure 10a), and joined with a reference spline. It was then loaded into the profile as a new family host copied to both points, where the form would be created (Figure 10b).
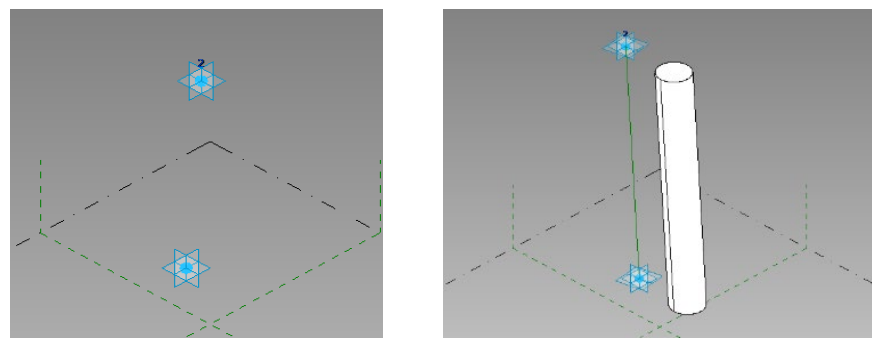

Figure 10: a. Two non-associated adaptive points were used to, b. Create the basic form for the structural support frame

\subsection{Assemblage}

The following steps explain the assembly process of the designed customisable façade system. The created panel will be placed on one corner of the mass (Figure 11a) and repeated to fill the mass in (Figure 11b). The parametric functions associated with the panel will automatically size and place it on the mesh uniquely sizes/shaped grids.
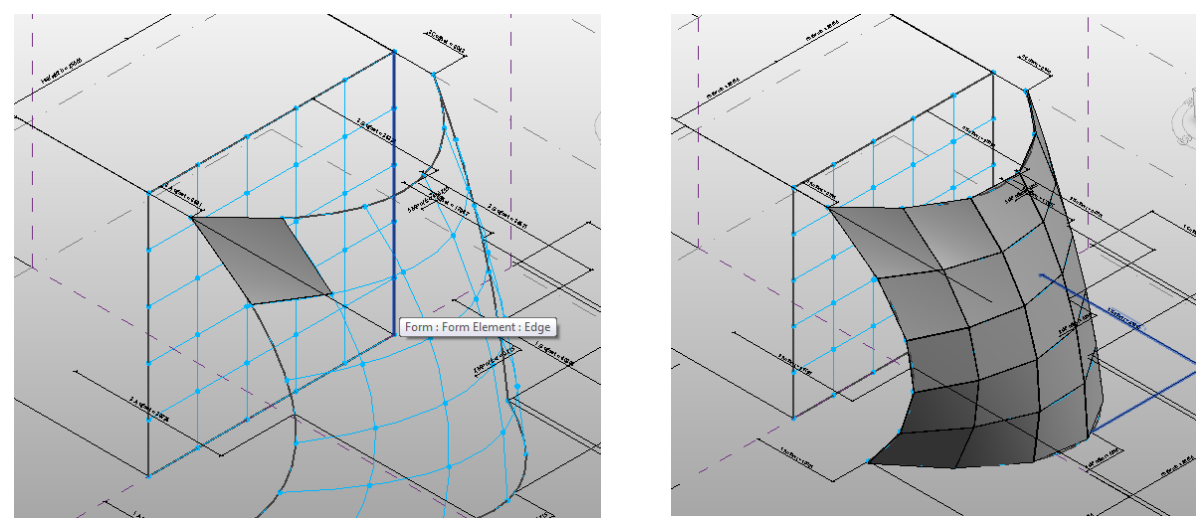

Figure 11: a. The façade panel is placed on the corner of the Tier1 surface-generator, $b$. It will be repeated to parametrically fit the different angles and sizes of each mesh grid

The same process will then be repeated for both support systems required (Figure 12).

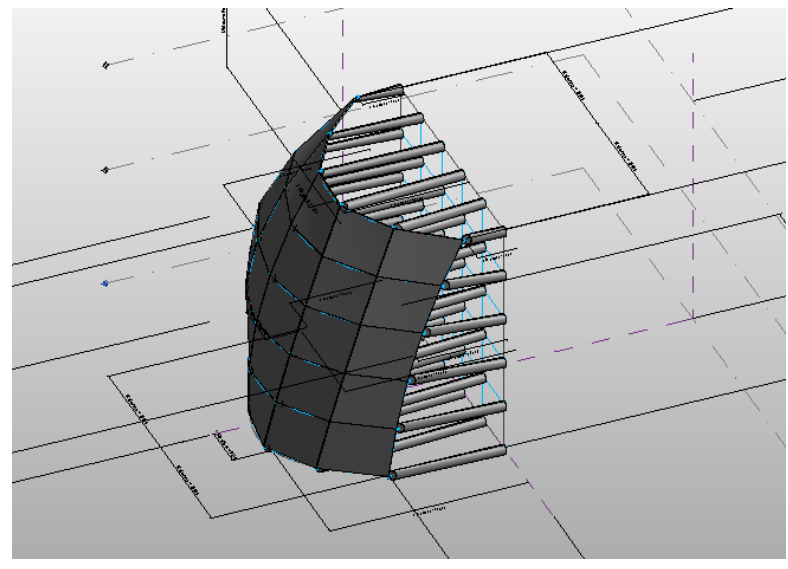


Figure 12: The façade support system for a fully customisable curtain wall façade

Nonetheless, this may be deemed over-design due to the number and repetition pattern of the support arms for the façade support structure. To address this issue, the number of individual support arms may be reduced to one consolidated support structure that can be connected to the main structure using less frequent support arms.

The proposed solution has several practical applications for establishing a fully customisable façade system due to its high flexibility which enhances its capability to accommodate variations in size, angle and direction. Hence, it can offer a fully off-site solution to what has otherwise been done manually (see Figure 13). Jakob-Kaiser-Haus, Bundestag, Berlin, is an indicative real case example of how this proposed model could have been utilised in, and applied to, a live project to potentially offer a wider choice in design, better information flow management, easier, faster and cheaper design, manufacturing, and assembly processes through enhancement of collaborative working processes facilitated by the proposed configuration platform.
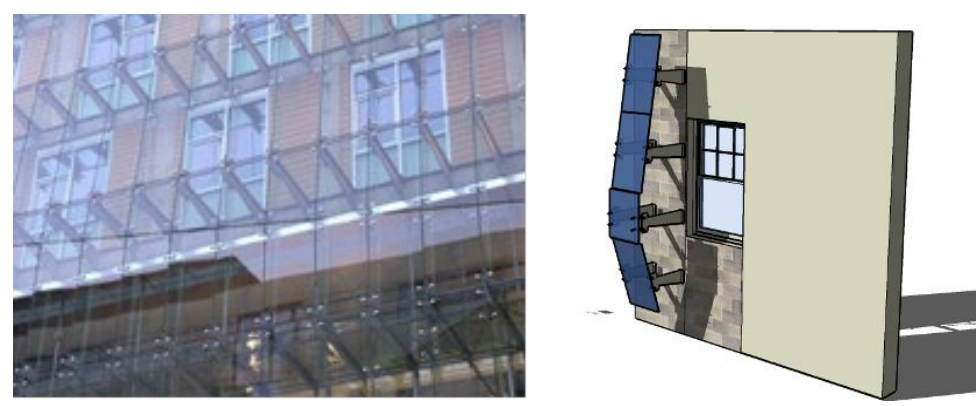

Figure 13: Jakob-Kaiser-Haus, Bundestag, Berlin

\section{Discussion of Findings}

The contribution of this research project consists of two distinct parts: 1) the development of the case model, and 2) the internal evaluation of the model and how it can respond to the challenges facing BIM in the construction industry. The development of the model was explained in section 7. This section particularly discusses how the proposed model can potentially facilitate better implementation and wider uptake of off-site construction with reference to BIM challenges.

The proposed model was reviewed within the research team and assessed internally against the perceived benefits of, and challenges facing, BIM in the AEC industry as reported in the literature. A likelihood matrix was devised so that all those benefits and challenges the proposed model may bring up can be assessed accordingly. In addition, the ways in which the proposed model may help tackle those challenges or improve those benefits were discussed. The likelihood and the ways in which both challenges and benefits may be affected by this proposed model as a configuration platform have been presented in separate tables. The benefits and challenges are aligned with literature; benefits such as increased building performance and quality, improved collaboration, earlier collaboration of multiple design disciplines (Design stage), better implementation of lean construction techniques (construction and fabrication), broader strategic perspective and innovation; and challenges including lack of industry standards and poor integration with existing systems, to name but a few. Comprehensive list of challenges associated with BIM which are likely to be addressed by the proposed platform is provided in table 1 .

Table 1: Industry challenges associated with BIM and how the proposed model may help in overcoming these hurdles 
Use of the model facilitates overcoming of BIM challenges

\begin{tabular}{lll}
$\begin{array}{l}\text { Specific industry challenges } \\
\text { with respect to BIM }\end{array}$ & $\begin{array}{c}\text { Likelihood of } \\
\text { model helping } \\
\text { tackle this } \\
\text { challenge }\end{array}$ & \multicolumn{1}{c}{ How the model may help? } \\
\hline Lack of industry standards & Highly Likely & $\begin{array}{l}\text { This challenge will be addressed to a great extent by modularising the } \\
\text { product portfolio. This will potentially contribute to BIM } \\
\text { standardisation, with some prospects to feed into Industry Foundation } \\
\text { Classes (IFC) and Construction Operations Building Information } \\
\text { Exchange (COBie) by means of visualisation of such standards in form } \\
\text { of a virtual product with ready-to-produce capabilities as and when } \\
\text { required }\end{array}$ \\
\hline
\end{tabular}

Greater system complexity Highly Likely To determine a proper scope before initiating the project and also modularising the product portfolio itself which will help significantly to reduce uncertainty and subsequently bring down the level of complexity.

The systems theory underpinning the proposed model will provide a great opportunity to break down complex multi-component façades to their constituent components. This will contribute to address and break down the complexity inherent in some advanced façade systems into smaller sub-components with lower degrees of complexity involved.

Different needs across Likely stakeholders

During scoping process of the project and standardisation of the product, the stakeholders' views, priorities and requirements are aligned at the core of this multi-disciplined project. Configurability requires an improved alignment of all requirements and constraints across organisation.

The systemic approach to platform design and configuration concept sets the boundaries out quite clearly and helps different stakeholders with diverse range of expertise, skills and experience understand how and where they can expect their unique design intents or building performance requirements to be fulfilled, by which means and to what extents.

Poor integration with Highly Likely
existing systems

The model requires high level of details at components and assembly levels. This, combined with a flexible and customisable interface system, should reduce the risk of lack of integration between the proposed solutions with existing systems.

This challenge seems to have been attempted on early on when BIM was introduced but so far very little progress has been made in this regard. The systemic approach underpinning the proposed platform design and configuration system in this study will resolve some of problems with poor integration by promoting standardisation and IT platform connectivity.

Unclear business value and ROI [return on investment]

Somewhat Likely
The proposed model may be perceived costly to begin with. However, with a pure approach inspired by the ones established in manufacturing industries, the man-hours (added and saved as a result of introduction of this new model solution) should be easily calculated and demonstrated that ROI is viable and worth adopting this model.

Although BIM has already been introduced to the AEC industry for good few years, it is yet expected to achieve its full potentials subject to readiness in the industry. The industry seems to be ready to embrace BIM practical benefits. If BIM is deployed to facilitate configuration for promoting customisation in the AEC industry, some such practical benefits will materialise and help its wider acceptance. By calculating only the saved man-hours still a great business case can be made to attract attention from the management and client teams. 
The complete list of advantages of BIM in the AEC industry were reported and extrapolated with customisation, product platform and configuration in the literature review of this study. They are evaluated for the likelihood of their contribution in gaining potential benefits and the ways in which such benefits may materialise in table 2 .

Table 2: BIM advantages and how the proposed model may help gain the potential benefits 
Use of the model increases the benefits and advantages of BIM

\begin{tabular}{l}
$\begin{array}{c}\text { BIM Advantages and } \\
\text { Benefits }\end{array}$ \\
\hline $\begin{array}{l}\text { Increased building } \\
\text { performance and quality }\end{array}$ \\
Improved collaboration \\
using integrated project \\
delivery
\end{tabular}

Earlier collaboration of multiple design disciplines

\author{
Likelihood of \\ model helping \\ improve the \\ advantages \\ and benefits \\ How the model may help?
}

By developing a schematic model prior to generating a detailed building model to evaluate the compliance with building performance and sustainability requirements.

Standardisation of products and components for proposed configurable model will provide improved post-occupancy maintenance and repair procedures, possibilities to replace components with higher-spec ones as and when they are required and available. Accordingly, the configurators limit the solution space of customisability and limit the manufacturers to the available product platforms which has a positive impact on the maintenance and replacement of different components. This will increase the building service life, improve its performance monitoring and control and enhances the overall quality of indoor environment while reducing its environmental impact.

Not Likely Although the proposed model provides a platform that enhances the collaboration, this is not likely to be through improved use of integrated project delivery (IPD). As the common response of the AEC industry to the IPD still needs major work to be improved, thereby its uptake can be improved.

However, the systemic structure underlying the proposed platform will make the project (in this case the building façade) much easier to convey, comprehend and link to, for multi-partite cliental of the project and is expected to indirectly enhance collaboration (even though it is not necessarily through IPD as an exclusive project delivery route).

Likely The proposed model provides a visualised platform with a userfriendly and easy-to-use GUI where different design disciplines would be able to work in collaboration, more closely with each other and starting earlier in the process.

In addition to the visualisation capabilities inherent in the proposed BIM model, high standardisation associated with its configuration platform will help to present: 1 ) the final product as well as 2 ) its design, 3) production, and 4) assembly processes in a simple, clear and accessible manner. This allows for configurability and access by different stakeholders to different sub-components and at different design, production and assembly stages, which in return reduces conflict of interest and facilitates division of tasks thereby enhancing collaboration.

Highly Likely By embedding the design into BIM as the lifecycle process management tool, the links through a BIM-server to the automated advanced fabrication process will be facilitated.

Furthermore, BIM as a lifecycle information management hub will facilitate fabrication process, re-production of damaged components or the ones in need of performance improvement with similar geometrical specifications but different and/or improved aesthetics or performance requirements.

Likely Improving the process and product efficiency, this model will provide an interactive real-time monitoring tool to reduce material and nonmaterial wastes and an effective tool for continuous improvement.

Moreover, at an upper level, this model can facilitate building a repository of configurable components for a fully customisable
Better implementation of lean construction techniques 


\section{Broader strategic perspective and innovation}

Easier to achieve process standardisation

\author{
More reliable compliance \\ with specification and \\ regulations
}

Improved communication and collaboration amongst project participants

Greater productivity from labour and assets

Decreased labour costs façade; a library which will be fed into and grow over time and reduce the need for designing similar elements from scratch. Knowledge, skill and expertise accumulation will reduce the need for rework, problem solving, snagging, ratification and will reduce the hand-over time and problems during post-occupancy periods.

Likely Modularising the product profile will help materialising all the benefits of one product strand and helps gestate new innovative product profiles which can meet more demanding requirements and higher standards.

Using the principles of platform deign, the model proposed in this study also lays down the foundations for a better, more-improved system. Additionally, repetitive problems can be avoided and the time usually spent on rectifying such problems can be spent on strategic innovation in design, implementation, and development of the system and application of advanced and emerging materials.

Highly Likely Benefits associated with standardisation have already started materialising through component libraries provided by material providers and component vendors. This open-source platform helps materialise those benefits even further by providing access to material and system suppliers to act as system developers to adopt and adapt and add to, extend and/or amend the generic platform further to best accommodate their unique products. This will be facilitated using the principles of co-design, co-creation and codevelopment.

N/A As discussed in the Research Design and Methodology, it is assumed that the products of this platform meet the minimum requirements of ones produced through conventional methods.

N/A Although there are clear offerings for better, more effective and more in-time communication through improved collaborative processes using this platform, this is not the main focus of this paper. Moreover, the collaboration will be efficient as the waiting times will be reduced and unproductive meetings will be avoided due to the automation.

Highly Likely Providing a higher opportunity to bring the production, assembly and construction problems back to the drawing board, this platform offers an outstanding opportunity to reduce failure and waste and increase lean productivity for both labour and assets.

Knowledge share, expertise exchange, task assignment and skill accumulation facilitated through the proposed platform will reduce lead time, time needed for rework, repair and trouble-shooting, and in return reduces the amount of waste in project time, human resources and materials.

Likely By providing a full product profile, the overall cost associated with the production of the façade systems will be reduced. The lead-time and design costs may increase but these will be negligible compared to savings in labour cost and time later in the process, due to economies of scale benefits offered through customisation of the mass-produced platforms into final personalised products.

Division of labour into the common labour needed to produced common-shared platform and the specialised labour needed for production, handling, transportation and assembly of fully customised elements will make the construct of the labour involved much clearer, more manageable, and last but not least more affordable.

\section{Concluding comments and future research}

Mass customisation and personalisation [(M)CP] are established customer-centric strategies in service and manufacturing industries. Despite the fact that the AEC industry is now past mass 
production of spaces and places era, it has not yet fully adopted (M)CP strategies. This is due to several reasons such as the nature of the AEC industry, fragmentation in its supply chain, distinct supply-demand equilibrium, structure of push/pull mechanism, resistance to change in the industry, lack of pressing need to adopt cutting-edge technologies and new materials, as well as availability and affordability of advanced ICT, fabrication, and assembly technologies, to name but a few. Another rather important but less researched underlying reason is the way in which modularity has conventionally been perceived and developed in the AEC industry. In the past two decades, a shift has started to look at the building drawings and models above and beyond traditional construction documentation. BIM has had a crucial role in this reconsideration and has started to transform the ways in which buildings are conceived, designed, constructed, delivered, operated, managed, maintained, refurbished, deconstructed and recycled. BIM has manifold benefits not only as a software package or an application, but as a tool, a platform and an environment which promises culture change in the AEC industry. BIM, as a platform, is of exclusive importance to this study because of two main reasons. Firstly, it provides an affordable ICT infrastructure required if any major advancement is to be made in the AEC industry; and secondly, because as a platform it offers an opportunity to re-read and facilitates a new understanding of the notions of module and modularity, product architecture and platform design in the AEC industry. Literature on BIM, product platform and configuration, and $(\mathrm{M}) \mathrm{CP}$ with special reference to specific aspects pertaining to modularity were reviewed to find connexions and overlaps which can facilitate or be facilitated by one another.

A case study was prototyped at the first stage of this research as a generic host with potentials to accommodate a fully customisable curtain wall façade system, using a systemic construct (based on Systems Theory). This was utilised to demonstrate the capabilities this system made promises to offer. To do so, one of the possible variations of such fully customisable curtain wall façade system was developed and tested with an emphasis on how the connections/joints between the platform and modular units can be managed. As per the systemic approach developed for this study, current paper focuses on the sub-system level joint components, which connect the system level façade to super-system building structures. This study shows that the initial host developed has capacities to be further developed beyond just a conceptual platform to actually accommodate real façade support system, façade panelised system with all its associated elements, components and materials as well as the connections as the façade support system. The principles of the developed support system is one of the many possible options and can further be developed into other alternatives through optimisation of the support elements, their sizes, their details and their connection types according to the building's structural system, the façade size, geometry and form as well as the variation in materials, connections and openings.

This paper contributes to advancing what was promised as one of the future developments in an earlier publication which addressed earlier stages of this research by:

- Devising an open-access non-proprietary platform which can be adopted and adapted by several users in different stakeholder groups either as common tool for developing design, manufacturing and assembly stages of a single project by a multi-partite project team or as a common tool to develop a single product or component by a number of stakeholders at the same level and with the same interest and expertise e.g. material or product suppliers and/or building, support or façade system providers;

- Demonstrating how such an open platform can be adopted and adapted using a case example. 
- Internally and critically evaluate the system and assess it against the perceived benefits of BIM as a digital platform (which has been used to develop this production platform) and the challenges BIM is understood to be faced with in the AEC industry;

- Laying down the foundations for a fully automated approach to construction processes (with special reference to production process of systemised building façades);

- Facilitating and promoting the uptake of BIM by applying it to real-case scenarios with tangible benefits;

- Promoting multi-disciplinarity in AEC research by bridging the gap in BIM application and utilising it to facilitate (M)CP of full parametric configurable façades.

This study also contributes to future research at sub-system level by:

- Introducing variation of materials for façade panels;

- Introducing alternative façade support structures;

- Accommodating the joints and connections between those materials and the framing supports in the façade panels;

- Offering opportunities for façade elements/components to accommodate Integrated Façade Systems (IFS) e.g. PV integrated shading devices, etc. where and when deemed required;

- Offering interchangeable kinetic façade elements/components.

It can also contribute to future research at system level by:

- Introducing substitute façade host to accommodate alternative façade support systems;

- Establishing new façade system to enable accommodating Integrated Façade Systems (IFS);

- Devising an alternative façade platform for kinematic modules;

- Introducing a new customisable façade system for adding Double Skin Façades (DSF) in refurbishment projects.

At super-system level, further research can address:

- The variation of structural systems and how the façade system can be integrated with them;

- The relative location of the curtain wall system to the structural system (or the DSF to the existing façade);

- The prefabricated/off-site connections between the façade support system and the structural system (with special reference to cold-bridging, heat and noise transfer, maintenance, lateral loads, etc.).

Furthermore, at service level, future research will also need to address:

- Automation in production and assembly of customisable curtain wall system;

- Investigations into interfaces with, and links to XML/HTML files and/or SQL databases and/or spread-sheets/data-sheets to create a web-based or standalone application with an easy-touse and user-friendly GUI for mass customisation of façades;

- The application of AR/VR in improvement of the customer experience and also to assist with two previous areas.

Another area for future research will be the links between Level of Detail (LoD) and Level of Information (Lol) with the proposed configuration platform to further investigate if such links can be established, then what LOD and Lol levels will be required at different stages of design, manufacturing and assembly of the proposed façade system using this product configuration platform. 
BIM has a vast array of capacities to be exploited. If it is comprehended and applied accordingly, it can prove to be instrumental not only as a new technology but as a major driver for a fundamental culture change in the AEC industry. One of such avenues for change is what BIM can offer - as a configuration platform - to enable a real-time (M)CP strategy in the AEC industry. This can and will introduce a major paradigm shift in the entire industry where the production process can massively move on to benefitting from precision, timeliness, improved quality, automated and unmanned production, fabrication, construction and assembly processes, agility, Lean Construction, JIT (Just-inTime), BTO (Build-to-Order), MTO (Made-to-Order), ETO (Engineer-to-Order), co-creation of design, knowledge and values. It will promise to revolutionise the common and conventional ways in which buildings are currently conceived, specified, constructed and operated to new ways and alternative solutions by which they can be ordered, fabricated and assembled. Furthermore and more importantly this will transform the ways in which buildings perform, are maintained, run, refurbished - throughout their lifecycle - and then - at the end of their service life - are decommissioned, disassembled and recycled.

It is worth mentioning that this study has its own boundaries and to some certain extents its own limits like any other study. The proposed method in the production process of a (customisable) façade system is assumed to utilise all the similar design intents, deliver to the same constructability principles and meet all the standards, codes, and legislations as well as performance requirements at least at, if not exceeding, the levels that are expected from a similar building product/component/element produced using conventional methods. Needless to say that technical, legal and liability issues, building performance, building codes, standards and legislations associated with the case of this study, are all issues which can further be scrutinised as the future studies and with a particular emphasis on BIM or configuration platforms or both. However, this study does not intend to cover all those pertaining aspects or arising issues as a result of this proposed platform. Those areas, although totally valid and worth investigating, are more realistically likely to be scrutinised in enough depth in a series of independent but interrelated follow-on studies on and around the proposed solution in this study.

\section{References}

[1] G. Herbert, The dream of the factory-made house : Walter Gropius and Konrad Wachsmann, MIT, Cambridge, Mass. ; London, 1984.

[2] F. Alizon, S.B. Shooter, T.W. Simpson, Henry Ford and the Model T: lessons for product platforming and mass customization, Design Studies 30 (5) (2009) 588-605 DOI: https://doi.org/10.1016/i.destud.2009.03.003.

[3] C. Eastman, P. Teicholz, R. Sacks, K. Liston, BIM Handbook: A Guide to Building Information Modeling for Owners, Managers, Designers, Engineers and Contractors, 2nd ed., John Wiley and Sons Inc., Hoboken, NJ, 2011.

[4] E.R.P. Farr, P.A.E. Piroozfar, D. Robinson, BIM as a generic configurator for facilitation of customisation in the AEC industry, Automation in Construction 45 (Supplement C) (2014) 119125 DOI: https://doi.org/10.1016/j.autcon.2014.05.012.

[5] J.K. M. Fischer, The scope and role of information technology in construction, Proceedings of Japan Society of Civil Engineers 763 (2004) 1-8.

[6] V. Singh, N. Gu, X. Wang, A theoretical framework of a BIM-based multi-disciplinary collaboration platform, Automation in Construction 20 (2) (2011) 134-144 DOI: https://doi.org/10.1016/i.autcon.2010.09.011.

[7] G. Lee, R. Sacks, C.M. Eastman, Specifying parametric building object behavior (BOB) for a building information modeling system, Automation in Construction 15 (6) (2006) 758-776 DOI: https://doi.org/10.1016/i.autcon.2005.09.009. 
[8] T. Cerovsek, A review and outlook for a 'Building Information Model' (BIM): A multi-standpoint framework for technological development, Advanced Engineering Informatics 25 (2) (2011) 224244 DOI: https://doi.org/10.1016/j.aei.2010.06.003.

[9] M.M. Singh, A. Sawhney, A. Borrmann, Modular Coordination and BIM: Development of Rule Based Smart Building Components, Procedia Engineering 123 (2015) 519-527 DOI: https://doi.org/10.1016/i.proeng.2015.10.104.

[10] A. Haug, S. Shafiee, L. Hvam, The costs and benefits of product configuration projects in engineer-to-order companies, Computers in Industry 105 (2019) 133-142 DOI: https://doi.org/10.1016/i.compind.2018.11.005.

[11] R.K. Yin, Case study research : design and methods, Fifth edition. ed., Sage Publications, New York, London, 2013.

[12] C. Voss, N. Tsikriktsis, M. Frohlich, Case research in operations management, International Journal of Operations \& Management ProductionManagement 22 (2) (2002) 195-219 DOI: https://doi.org/10.1108/01443570210414329.

[13] P. Darke, G. Shanks, M. Broadbent, Successfully completing case study research: combining rigour, relevance and pragmatism, Information Systems Journal 8 (4) (1998) 273-289 DOI: https://doi.org/10.1046/i.1365-2575.1998.00040.x.

[14] J.W. Creswell, V.L.P. Clark, Designing and Conducting Mixed Methods Research, Sage Publications, Inc., Thousand Oaks, 2011.

[15] R.B. Johnson, A.J. Onwuegbuzie, L.A. Turner, Toward a Definition of Mixed Methods Research, Journal of Mixed Methods Research 1 (2) (2007) 112-133 DOI: https://doi.org/10.1177/1558689806298224.

[16] K.T. Ulrich, S.D. Eppinger, Product design and development, McGraw-Hill, New York ; London, 1995.

[17] K. Park, G.E. Okudan Kremer, Assessment of static complexity in design and manufacturing of a product family and its impact on manufacturing performance, International Journal of Production Economics 169 (2015) 215-232 DOI: https://doi.org/10.1016/j.ijpe.2015.07.036.

[18] M. Gelman, S. Kariv, M.D. Shapiro, D. Silverman, S. Tadelis, Growing modular: mass customization of complex products, services and software, Springer Science \& Business Media, 2005 DOI: https://doi.org/10.1007/b139063.

[19] K. Ulrich, The role of product architecture in the manufacturing firm, Research Policy 24 (24) (1995) 419-441 DOI: https://doi.org/10.1016/0048-7333(94)00775-3.

[20] J. Jiao, M.M. Tseng, Fundamentals of product family architecture, Integrated Manufacturing Systems 11 (7) (2000) 469-483 DOI: https://doi.org/10.1108/09576060010349776.

[21] M. Meyer, A. Lehnerd, The Power of Product Platforms: Building Value and Cost Leadership, The Free Press, New York, 1997.

[22] C. Thuesen, L. Hvam, Efficient on-site construction: learning points from a German platform for housing, Construction Innovation 11 (3) (2011) 338-355 DOI:

https://doi.org/10.1108/14714171111149043.

[23] A. Kudsk, L. Hvam, C. Thuesen, M.O.B. Grønvold, M.H. Olsen, Modularization in the Construction Industry Using a Top-Down Approach, The Open Construction and Building Technology Journal 7 (1) (2013) 99-107 DOI: https://doi.org/10.2174/1874836801307010088.

[24] L.d.A. Corrêa, F.I. Kubota, P.A.C. Miguel, Towards a contribution to modularity concepts and principal domains, Product Management and Development 10 (2) (2012) 119-130 DOI: http://dx.doi.org/10.4322/pmd.2013.006.

[25] Le Corbusier, The Modulor : A Harmonious Measure to the Human Scale Universally applicable to Architecture and Mechanics, Faber and Faber Limited, London, 1951.

[26] Le Corbusier, Modulor 21955 (let the user speak next) continuation of The Modular 1948, Faber and Faber, [S.I.], 1958. 
[27] P. Piroozfar, E.R.P. Farr, Evolution of Nontraditional Methods of Construction: 21st Century Pragmatic Viewpoint, Journal of Architectural Engineering 19 (2) (2013) 119-133 DOI: https://doi.org/10.1061/(ASCE)AE.1943-5568.0000078.

[28] P. Piroozfar, Mass-customisation: The Application on Design, Fabrication and Implementation (DFI) Processes of Building Envelopes, School of Architecture University of Sheffield 2008.

[29] K. Medini, Modularity and variety spinoffs: A supply chain planning perspective, International Journal of Industrial Engineering: Theory, Applications and Practice 22 (6) (2016) DOI: http://journals.sfu.ca/ijietap/index.php/ijie/article/view/2057.

[30] J. Bonvoisin, F. Halstenberg, T. Buchert, R. Stark, A systematic literature review on modular product design, Journal of Engineering Design 27 (7) (2016) 488-514 DOI:

https://doi.org/10.1080/09544828.2016.1166482.

[31] F.A.S. Piran, D.P. Lacerda, J.A.V. Antunes, C.F. Viero, A. Dresch, Modularization strategy: analysis of published articles on production and operations management (1999 to 2013), The International Journal of Advanced Manufacturing Technology 86 (1) (2016) 507-519 DOI: https://doi.org/10.1007/s00170-015-8221-9.

[32] K. Ulrich, K. Tung, Fundamentals of product modularity, 1991 ASME Winter Annual Meeting Symposium on Issues in Design/Manufacturing Integration, Atlanta, GA, USA, 1991.

[33] F. Erens, K. Verhulst, Architectures for product families, Computers in Industry 33 (2) (1997) 165-178 DOI: https://doi.org/10.1016/S0166-3615(97)00022-5.

[34] M. Zhang, H. Guo, B. Huo, X. Zhao, J. Huang, Linking supply chain quality integration with mass customization and product modularity, International Journal of Production Economics (2017) DOI: https://doi.org/10.1016/j.ijpe.2017.01.011.

[35] S.M. Johnsen, L. Hvam, Understanding the impact of non-standard customisations in an engineer-to-order context: A case study, International Journal of Production Research (2018) 115 DOI: https://doi.org/10.1080/00207543.2018.1471239.

[36] P. Kotler, From Mass Marketing to Mass Customization, Planning review 15 (5) (1989) 10-47 DOI: https://doi.org/10.1108/eb054267.

[37] H. ElMaraghy, G. Schuh, W. EIMaraghy, F. Piller, P. Schönsleben, M. Tseng, a. Bernard, Product variety management, CIRP Annals - Manufacturing Technology 62 (2) (2013) 629-652 DOI: https://doi.org/10.1016/j.cirp.2013.05.007.

[38] J. Vesanen, M. Raulas, Building bridges for personalization: A process model for marketing, Journal of Interactive Marketing 20 (1) (2006) 5-20 DOI: https://doi.org/10.1002/dir.20052.

[39] M. Ariano, A. Dagnino, An intelligent order entry and dynamic bill of materials system for manufacturing customized furniture, Computers \& Electrical Engineering 22 (1) (1996) 45-60 DOI: https://doi.org/10.1016/0045-7906(95)00027-5.

[40] V.E. Barker, D.E. O'Connor, J. Bachant, E. Soloway, Expert systems for configuration at Digital: XCON and beyond, Communications of the ACM 32 (3) (1989) 298-318 DOI: https://doi.org/10.1145/62065.62067.

[41] C. Forza, F. Salvador, Managing for variety in the order acquisition and fulfilment process: The contribution of product configuration systems, International Journal of Production Economics 76 (1) (2002) 87-98 DOI: https://doi.org/10.1016/S0925-5273(01)00157-8.

[42] A. Haug, L. Hvam, N.H. Mortensen, Definition and evaluation of product configurator development strategies, Computers in Industry 63 (5) (2012) 471-481 DOI: https://doi.org/10.1016/i.compind.2012.02.001.

[43] M. Heiskala, J. Tiihonen, K.S. Paloheimo, T. Soininen, Mass Customization with Configurable Products and Configurators, Mass Customization Information Systems in Business (2007) 1-32 DOI: https://doi.org/10.4018/978-1-59904-039-4.ch001.

[44] J. Tiihonen, T. Soininen, T. Männistö, R. Sulonen, Configurable Products - Lessons learned from the Finnish Industry, Proceedings of 2nd International Conference on Engineering Design and Automation, Integrated Technology Systems, Inc, Hawaii, 1998. 
[45] L. Ardissono, A. Felfernig, G. Friedrich, A. Goy, D. Jannach, G. Petrone, R. Schafer, M. Zanker, A Framework for the Development of Personalized, Distributed Web-Based Configuration Systems, Al Magazine 24 (3) (2003) 93-93 DOI: https://doi.org/10.1609/aimag.v24i3.1721.

[46] T. Blecker, N. Abdelkafi, G. Kreutler, G. Friedrich, Product configuration systems: state of the art, conceptualization and extensions, The Eight Maghrebian Conference on Software Engineering (MCSEAI 2004), 2004, pp. 25-36.

[47] A. Felfernig, G.E. Friedrich, D. Jannach, UML as domain specific language for the construction of knowledge-based configuration systems, International Journal of Software Engineering and Knowledge Engineering 10 (4) (2000) 449-469 DOI: https://doi.org/10.1016/S02181940(00)00024-9.

[48] J. Tiihonen, T. Soininen, T. Männistö, R. Sulonen, State-of-the-practice in product configuration - a survey of 10 cases in the Finnish industry, in: T. Tomiyama, M. Mäntylä, S. Finger (Eds.), Knowledge Intensive CAD: Volume 1, Springer US, Boston, MA, 1996, pp. 95-114 DOI: https://doi.org/10.1007/978-0-387-34930-5 7.

[49] K. Kristjansdottir, S. Shafiee, L. Hvam, M. Bonev, A. Myrodia, Return on investment from the use of product configuration systems - A case study, Computers in Industry 100 (2018) 57-69 DOI: https://doi.org/10.1016/i.compind.2018.04.003.

[50] J. Wikner, M. Rudberg, Integrating production and engineering perspectives on the customer order decoupling point, International Journal of Operations \& Production Management 25 (7) (2005) 623-623 DOI: https://doi.org/10.1108/01443570510605072.

[51] H.A. ElMaraghy, Reconfigurable process plans for responsive manufacturing systems, in: P.F. Cunha, P.G. Maropoulos (Eds.), Digital Enterprise Technology, Springer, Boston, 2007, pp. 35-44 DOI: https://doi.org/10.1007/978-0-387-49864-5 4.

[52] H. ElMaraghy, Changing and evolving products and systems-models and enablers, in: $\mathrm{H}$. EIMaraghy (Ed.), Changeable and Reconfigurable Manufacturing Systems., Springer, London, 2009, pp. 25-45 DOI: https://doi.org/10.1007/978-1-84882-067-8 2.

[53] D. Kumar, W. Chen, T.W. Simpson, A market-driven approach to product family design, International Journal of Production Research 47 (1) (2009) 71-104 DOI: https://doi.org/10.1080/00207540701393171.

[54] R. Sanchez, Building real modularity competence in automotive design, development, production, and after-service, International Journal of Automotive Technology and Management 13 (3) (2013) 204-236 DOI: https://doi.org/10.1504/IJATM.2013.054918.

[55] L. Hvam, N.H. Mortensen, J. Riis, Product customization, Springer Science \& Business Media., 2008 DOI: https://doi.org/10.1007/978-3-540-71449-1.

[56] M. Bonev, L. Hvam, J. Clarkson, A. Maier, Formal computer-aided product family architecture design for mass customization, Computers in Industry 74 (2015) 58-70 DOI: https://doi.org/10.1016/j.compind.2015.07.006.

[57] A. Felfernig, L. Hotz, C. Bagley, J. Tiihonen, Knowledge-Based Configuration From Research to Business Cases, Morgan Kaufman, Newnes, 2014 DOI: https://doi.org/10.1016/B978-0-12415817-7.00029-3.

[58] C. Forza, F. Salvador, Product information management for mass customization: connecting customer, front-office and back-office for fast and efficient customization, Palgrave Macmillan, New York, 2007.

[59] W.J.C. Verhagen, B. de Vrught, J. Schut, R. Curran, A method for identification of automation potential through modelling of engineering processes and quantification of information waste, Advanced Engineering Informatics 29 (3) (2015) 307-321 DOI: https://doi.org/10.1016/j.aei.2015.03.003.

[60] T.D. Petersen, Product Configuration in ETO Companies, Igi Global, 2007, pp. 59-76 DOI: https://doi.org/10.4018/978-1-59904-039-4.ch003. 
[61] R. Rai, V. Allada, Modular product family design: Agent-based Pareto-optimization and quality loss function-based post-optimal analysis, International Journal of Production Research 41 (17) (2003) 4075-4098 DOI: https://doi.org/10.1080/0020754031000149248.

[62] T.W. Simpson, C.C. Seepersad, F. Mistree, Balancing Commonality and Performance within the Concurrent Design of Multiple Products in a Product Family, Concurrent Engineering 9 (3) (2001) 177-190 DOI: https://doi.org/10.1106/t4h4-e0at-p6xl-0u7h.

[63] B.J. Pine, Mass customization: the new frontier in business competition, Harvard Business Press, 1993.

[64] Q. Tu, M.A. Vonderembse, T.S. Ragu-Nathan, B. Ragu-Nathan, Measuring Modularity-Based Manufacturing Practices and Their Impact on Mass Customization Capability: A CustomerDriven Perspective, Decision Sciences 35 (2) (2004) 147-168 DOI: https://doi.org/10.1111/i.00117315.2004.02663.x.

[65] Z. Wang, M. Zhang, H. Sun, G. Zhu, Effects of standardization and innovation on mass customization: An empirical investigation, Technovation 48-49 (2016) 79-86 DOI: https://doi.org/10.1016/j.technovation.2016.01.003.

[66] K. Ulrich, Fundamentals of Product Modularity, in: S. Dasu, C. Eastman (Eds.), Management of Design: Engineering and Management Perspectives, Springer Netherlands, Dordrecht, 1994, pp. 219-231 DOI: https://doi.org/10.1007/978-94-011-1390-8 12.

[67] W.J. Abernathy, J.M. Utterback, Patterns of industrial innovation, Technology Reviews (80) (1978) 40-47.

[68] WBDG, Building Information Modeling (BIM) in: National Institute of Building Sciences (Ed.), National Institute of Building Sciences, Washington DC, 2016.

[69] FMI/CMAA, Eighth Annual Survey of Owners 2007, CMAA Foundation, McLean (VA), 2007.

[70] M. de Reuver, C. Sørensen, R.C. Basole, The digital platform: a research agenda, Journal of Information Technology 33 (2) (2018) 124-135 DOI: https://doi.org/10.1057/s41265-016-00333.

[71] S.-c. Chien, T.-c. Chuang, H.-S. Yu, Y. Han, B.H. Soong, K.J. Tseng, Implementation of Cloud BIMbased Platform Towards High-performance Building Services, Procedia Environmental Sciences 38 (2017) 436-444 DOI: https://doi.org/10.1016/j.proenv.2017.03.129.

[72] O. Davtalab, A. Kazemian, B. Khoshnevis, Perspectives on a BIM-integrated software platform for robotic construction through Contour Crafting, Automation in Construction 89 (2018) 13-23 DOI: https://doi.org/10.1016/j.autcon.2018.01.006.

[73] Z. Ma, Z. Liu, Ontology- and freeware-based platform for rapid development of BIM applications with reasoning support, Automation in Construction 90 (2018) 1-8 DOI: https://doi.org/10.1016/i.autcon.2018.02.004.

[74] C.Z. Li, F. Xue, X. Li, J. Hong, G.Q. Shen, An Internet of Things-enabled BIM platform for on-site assembly services in prefabricated construction, Automation in Construction 89 (2018) 146-161 DOI: https://doi.org/10.1016/i.autcon.2018.01.001.

[75] R. Barak, Y.-S. Jeong, R. Sacks, C.M. Eastman, Unique Requirements of Building Information Modeling for Cast-in-Place Reinforced Concrete, Journal of Computing in Civil Engineering 23 (2) (2009) 64-74 DOI: https://doi.org/10.1061/(ASCE)0887-3801(2009)23:2(64).

[76] BuildingSMART Alliance, National Institute of Building Sciences, United States Building Information Modeling Standard, Part 1: Overview, Principles, and Methodologies, 2007.

[77] S. Aram, C. Eastman, R. Sacks, Requirements for BIM platforms in the concrete reinforcement supply chain, Automation in Construction 35 (2013) 1-17 DOI: https://doi.org/10.1016/i.autcon.2013.01.013. 
